\title{
Evolution of the structural and bonding properties of Aluminum-Lithium clusters
}

\author{
S. Chacko ${ }^{\dagger}$, D. G. Kanhere \\ Department of Physics, University of Pune, Pune 411 00\%, India. \\ V. V. Paranjape, \\ Department of Physics, Lakehead University, Thunder Bay, Ontario, P7B 5E1 Canada.
}

(November 8, 2018)

\begin{abstract}
We present a systematic study of the geometries, energetics, electronic structure and bonding in various $\mathrm{Al}-\mathrm{Li}$ clusters viz. $\mathrm{Al}_{n} \mathrm{Li}_{n}(n=1-11), \mathrm{Al}_{2}^{-}$, $\mathrm{Al}_{2}^{2-}, \mathrm{Al}_{2} \mathrm{Li}, \mathrm{Al}_{2} \mathrm{Li}^{-}$, and $\mathrm{Al}_{6} \mathrm{Li}_{8}$ using Born-Oppenheimer molecular dynamics within the framework of density functional theory. The growth pattern in these clusters is divided in two broad categories: the first one consisting of a bent rhombus of $\mathrm{Al}_{2} \mathrm{Li}_{2}(n=2-4)$ and the second one consisting of a pentagonal ring $(n=7-9,11)$. A substantial charge transfer is seen in nearly all clusters with the exception of $\mathrm{Al}_{2} \mathrm{Li}_{2}$ where the charge transfer is not significant. In clusters with more than six $\mathrm{Al}$ atoms, the eigenvalue spectrum is divided into two groups: a lower group of jellium-like states and a higher group of localized bonds formed through the interaction of the $p$ electrons on each of the $\mathrm{Al}$ atoms. Finally, we have discussed the tetravalent behavior of $\mathrm{Al}$ atoms arising due to a charge transfer from the $\mathrm{Li}$ atoms to the $\mathrm{Al}$ atoms.
\end{abstract}

Typeset using REVTEX 


\section{INTRODUCTION}

The discovery of $\mathrm{C}_{60}$ buckminsterfullerene [1], observation of magicity in metallic clusters [2], unusual thermodynamical properties of clusters of atoms like $\mathrm{Na}$ [3], Sn [4] etc., has given rise to an explosive growth of research in the field of cluster physics. Extensive theoretical and experimental [5-7] work has been carried out to understand the physical and chemical properties of clusters like size-evolutionary pattern in cluster geometry, thermodynamics, vibrational and rotational properties, optical properties, electronic structure, and bonding, chemical reactivity, as well as the emergence of the bulk properties with the increase in cluster size.

Recently observed aromaticity [8] and antiaromaticity [9-12] in inorganic molecules, and in particular Al-Li clusters, has stimulated further research in these systems. These properties are well-known and important in organic chemistry [13]. However, recently the first

experimental and theoretical evidence of aromaticity in all-metal system viz. $\mathrm{Al}_{4}^{2-}$ and $\mathrm{MAl}_{4}^{-}(M=\mathrm{Li}, \mathrm{Na}, \mathrm{Cu})$ was reported by Wang and coworkers [8]. They found the $\mathrm{Al}_{4}^{2-}$ dianion to be square-planar possessing two $\pi$-electrons, thus conforming the structural criterion for aromaticity. The concept of antiaromaticity, introduced by Breslow [14] et al., corresponds to the destabilization seen in the cyclic systems with $4 n \pi$-electrons. Although such molecules have not yet been observed except in organic chemistry, calculations reported by Shetty $[9,11]$ et al. and others [12] indicate the $\mathrm{Al}_{4} \mathrm{Li}_{4}$ cluster to be antiaromatic.

Aluminum-lithium clusters, which we study in this paper, are also interesting due to their unusual structural and bonding properties that are quite different from those of the pure clusters of the constituent elements. Both pure Al and Li clusters have been extensively studied using the spherical jellium model (SJM) [2]. However, it is observed that although the SJM has been quite successful in describing the gross electronic structure and the stability of alkali metal atom clusters [2,15], the Al clusters present an interesting contrast. Rao and Jena [16] have reported a comprehensive study of the aluminum cluster using $a b$ initio density functional theory. They found that in small Al clusters, the effective valency 
of $\mathrm{Al}$ is one [16] due to a large energy gap of about $5 \mathrm{eV}$ separating the $3 s^{2}$ and $3 p^{1}$ orbitals. However, Rao [17] et al. as well as Dhavale [18] et al. did not find any signature of such monovalent behavior, contrary to the expectations. Investigation by Cheng [19] et al. shows that a single $\mathrm{Al}$ atom in $\mathrm{Li}$ clusters introduces a localized bond between the $\mathrm{Al}$ impurity and the Li host. They also found a magic cluster $\mathrm{AlLi}_{5}$, and suggested that $\mathrm{Al}_{n} \mathrm{Li}_{5 n}$ can aggregate at least for some values of $n \geq 2$ and may exhibit properties characteristic to an assembly of such clusters from the $\mathrm{AlLi}_{5}$ subunits. Akola [20] et al., however, found that this idea does not apply after $n=2$. Further, their investigation on bonding in Li-rich Al-Li clusters show a substantial charge transfer from Li atom and nearby $\mathrm{Al}$ atom, strengthening the ionic Al-Li bond, while the Al-Al bond gained a more covalent nature. Such a charge transfer has been observed by Kumar [21] in several mixed Al-Li clusters. He found a layered $\mathrm{Al}_{10} \mathrm{Li}_{8}$ compound to be magic with electronic and geometric shell closing. This was the first instance where a shell closure in $s-p$ bonded metal cluster was found to occur at 38 valence electrons. Note that the magic numbers for alkali metal atom clusters [2] are 2, 8, $18,20,40, \ldots$, whereas, some of the magic $\mathrm{Al}$ clusters are $\mathrm{Al}_{7}^{+}, \mathrm{Al}_{7}^{-}, \mathrm{Al}_{11}^{-}, \mathrm{Al}_{13}^{-}$, etc $[16,22]$.

The Al-Li bulk is especially interesting due to the fact that it forms a stable alloy at over the wide range of concentration. However, the most stable intermetallic B32 phase corresponds to the 50:50 concentration [23]. In this B32 phase, a mixture of covalent and ionic bonding is seen due to a remarkable charge transfer from the Li atoms to the $\mathrm{Al}$ atoms. Moreover, the close resemblance of the density of states (DOS) (without any band gap) [24] to that of the covalently bonded diamond structure indicates a tetravalent behavior of $\mathrm{Al}$ atom. Thus, based on these observations, one can expect that the behavior of $\mathrm{Al}$ in $\mathrm{Al}_{n} \mathrm{Li}_{n}$ clusters would be similar to that of the tetravalent atom Si [25], Ge [26], Sn, and $\mathrm{Pb}$ [27]. Indeed, our present work shows that in certain clusters, structure and bonding of $\mathrm{Al}_{n}$ is similar to that of the group IV A clusters. Moreover, earlier work on the heterogeneous Al-Li clusters has focussed on specific aspects like systematics in the geometry, stability, shell closure, magic behavior etc. Bonding in such clusters was discussed on the basis of total charge density as well as the difference of the self-consistent charge density, $\rho_{s c f}$, and 
the superimposed atomic charge densities $\rho_{\text {superimposed }}$ of the constituent atoms. On the contrary, analysis of the molecular orbitals (MOs) has revealed some unusual properties like aromaticity and antiaromaticity in all-metal Al-Li clusters. In our earlier work, we have examined some of the issues concerning the geometry and the stability of various AlLi clusters viz. $\operatorname{Al}_{n} \operatorname{Li}_{n}(n=, 1-10,13)$ [28], $\operatorname{Al}_{n} \operatorname{Li}_{7}(n=1-7)$ [29], $\operatorname{AlLi}_{n}(n=1,8)$ [29] and $\mathrm{Al}_{13} \mathrm{Li}_{n}(n=1-4,10,19,20,21)[30]$. We have found that the geometries of these clusters were dictated by the geometry of the core $\mathrm{Al}$ cluster, enclosed in the Li cage. However, since these calculations were performed by the density based molecular dynamics (DBMD), an analyses of the bonding and electronic structure could not be done. In the present work, we study the systematics of the geometries, energetics, electronic structure and the bonding properties in various $\mathrm{Al}-\mathrm{Li}$ clusters viz. $\mathrm{Al}_{n} \mathrm{Li}_{n}(n=1-11), \mathrm{Al}_{2}^{-}, \mathrm{Al}_{2}^{2-}, \mathrm{Al}_{2} \mathrm{Li}_{2} \mathrm{Al}_{2} \mathrm{Li}^{-}$, and $\mathrm{Al}_{6} \mathrm{Li}_{8}$ using Kohn-Sham formulation of the density functional theory (DFT) within the pseudopotential and the generalized gradient approximation (GGA). The bonding in these clusters is analyzed via the electron localization function (ELF) [31] and the molecular orbitals. In section II we shall describe the computational details, followed by a discussion of the results in section III.

\section{COMPUTATIONAL DETAILS}

The ground state geometries as well as other low-lying structures were obtained in two stages. In the first stage, Born-Oppenheimer molecular dynamics (BOMD) [32] based on Kohn-Sham (KS) [33] formulation of density functional theory (DFT) was employed. The computer code used for this purpose was developed in our own group. The total energy during each of the molecular dynamics step was minimized using damped equation of motion [34]. The calculations were performed using norm-conserving pseudopotentials of Bachelet [35] et al., in the Kleinman-Bylander [36] form with $s$ part treated as nonlocal. The exchange-correlation potential was calculated using the local density approximation (LDA) given by Ceperley-Alder [37]. A cubic supercell of length 40a.u. with an energy cutoff of 
$\approx 17$ Rydberg was found to provide sufficient convergence of the total energy. Increasing the energy cutoff did not improve the total electronic energy significantly.

The damped equation of motion scheme [34] permits use of a fairly moderate time step ₹100a.u. Starting from a random configuration, the $\mathrm{Al}_{n} \mathrm{Li}_{n}$ clusters were heated to 1400$1700 \mathrm{~K}$, and allowed to span the phase space for a few thousand iterations. In our previous investigations [28-30] on $\mathrm{Al}_{n} \mathrm{Li}_{n}$ clusters, it was found that the $\mathrm{Li}$ atoms segregate at the surface with the $\mathrm{Al}$ atoms forming an inner core. In order to avoid any such segregation during the molecular dynamics run, we have interchanged the $\mathrm{Al}$ and the Li atoms. This has ensured that the cluster visits all its local minima as well as the global minimum. At the end of each ionic displacement, the norm of the eigenstates defined as $\left|h \psi_{i}-\epsilon_{i} \psi_{i}\right|^{2}$ (where $\epsilon_{i}$ is an eigenvalue corresponding to the eigenstate $\psi_{i}$ of the Kohn-Sham Hamiltonian h) was within the range of $10^{-4}-10^{-7}$ a.u.

In the second stage, various low-lying structures were obtained by conjugate gradient and/or steepest descent [32] method starting from various suitable configurations during the molecular dynamics run. These configurations were then optimized using ultrasoft pseudopotentials [38] within the generalized gradient approximation (GGA) implemented in the VASP [39] package. The Perdew-Wang [40] exchange-correlation potential for GGA has been used. The size of the simulation cell was varied according to the cluster studied (see Table-I).

Table - I

Size of the supercell (in $\AA$ ) for various clusters, where $n$ is the total number of atoms in the clusters. 


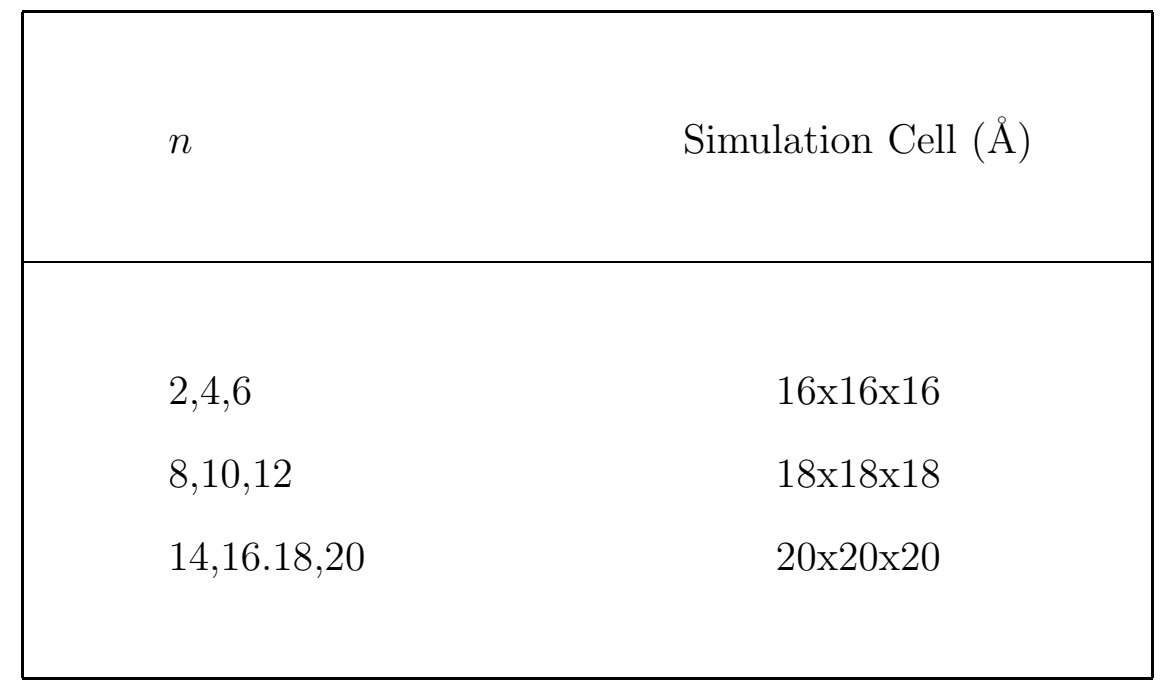

The geometries were optimized with a kinetic energy cutoff of the order of $\approx 12$ Rydbergs. This energy cutoff was sufficient for the convergence of the total energy. Increasing the energy cutoff did not improve the total electronic energy significantly. The structures were considered to have converged when the forces on each ion was less than $0.01 \mathrm{eV} / \AA$ with a convergence in the total energy within the range of $10^{-4}-10^{-6} \mathrm{eV}$. In general, we find that there are many isomeric structures nearly degenerate to the lowest energy state. Few of the structures can be obtained by interchanging the $\mathrm{Al}$ and the $\mathrm{Li}$ atoms or by rearranging the position of Li atoms. In the present work, we discuss only a few geometries corresponding to the lowest energies.

The nature of the bonding has been investigated using the electron localization function (ELF) [31] along with the molecular orbitals (MO) as well as the difference charge density. The ELFs have been found to be useful for elucidating the bonding characteristics of a variety of systems, especially in conjunction with the charge density. The value of the ELF lies between 0 and 1, where 1 represents a perfect localization of the valence charge density. The difference charge density is the difference between the self-consistent charge density, $\rho_{s c f}$, and the superimposed atomic charge densities, $\rho_{\text {superimposed }}$, of the constituent atoms. 


\section{RESULTS AND DISCUSSION}

\section{A. Structure, energetics and stability}

The ground state geometries and some of the low energy structures of $\mathrm{Al}_{n} \mathrm{Li}_{n}$, and $\mathrm{Al}_{6} \mathrm{Li}_{8}$ clusters are shown in figures $1\left(n=2-6\right.$, and $\left.\mathrm{Al}_{6} \mathrm{Li}_{8}\right)$, and $2(n=7-11)$. The ground state geometries are divided into two broad categories, for (i) $n=2-4$ (figures 1a(i)-1c(i)), and (ii) $n=7-9$, and 11 (figures $2 \mathrm{a}(\mathrm{i})-2 \mathrm{c}(\mathrm{i}), 2 \mathrm{e}(\mathrm{i})$ ), depending on the growth pattern. In the first category a quinted roof-like structure of $\mathrm{Al}_{2} \mathrm{Li}_{2}$ is seen (a quinted roof structure is a rhombus with a bend at its diagonal). The second category shows a pentagonal ring which is a signature of an icosahedral growth. The ground state geometries of $n=5,6$, and 10 clusters (figures 1d, 1e, 2d) show neither a quinted roof nor a pentagonal ring. In what follows, we discuss the structure and stability of these clusters. The stability is discussed via the binding energy $\left(\mathrm{E}_{b}\right)$, the dissociation energy $(\Delta \mathrm{E})$ and the second difference in the total energy with respect to a single Al-Li pair $\left(\Delta^{2} E\right)$, and the energy gap between the highest occupied molecular orbital (HOMO) and the lowest unoccupied molecular orbital (LUMO). These quantities are plotted in figure $3 \mathrm{a}\left(\mathrm{E}_{b}\right), 3 \mathrm{~b}\left(\Delta \mathrm{E}, \Delta^{2} \mathrm{E}\right)$, and 3c (HOMO-LUMO gap) as a function of the number of $\mathrm{Al}$ atoms in the cluster and are defined as

$$
\begin{array}{r}
\mathrm{E}_{b}\left[\mathrm{Al}_{n} \mathrm{Li}_{n}\right]=\left[-\mathrm{E}\left[\mathrm{Al}_{n} \mathrm{Li}_{n}\right]+n(\mathrm{E}[\mathrm{Al}]+\mathrm{E}[\mathrm{Li}])\right] / 2 n \\
\Delta \mathrm{E}\left[\mathrm{Al}_{n} \mathrm{Li}_{n}\right]=\left[\mathrm{E}\left[\mathrm{Al}_{n} \mathrm{Li}_{n}\right]-\mathrm{E}\left[\mathrm{Al}_{n-1} \mathrm{Li}_{n-1}\right]\right]-\mathrm{E}[\mathrm{Al} \mathrm{Li}] \\
\Delta^{2} \mathrm{E}\left[\mathrm{Al}_{n} \mathrm{Li}_{n}\right]=\left[\mathrm{E}\left[\mathrm{Al}_{n-1} \mathrm{Li}_{n-1}\right]-2 \mathrm{E}\left[\mathrm{Al}_{n} \mathrm{Li}_{n}\right]\right]-\mathrm{E}\left[\mathrm{Al}_{n+1} \mathrm{Li}_{n+1}\right]
\end{array}
$$

Let us recall that a pronounced maximum in the dissociation energy $\Delta \mathrm{E}$, along with a corresponding minimum in $\Delta^{2} \mathrm{E}$, signifies stability. In addition, in figure $3 \mathrm{~d}$, we have plotted the smallest bond distances of Al-Al, Al-Li and Li-Li as a function of the number of Al atoms in the cluster.

The ground state geometry of $\mathrm{Al}_{2} \mathrm{Li}_{2}$ is a bent rhombus (figure 1a(i)). The planar geometry (figure $1 \mathrm{a}(\mathrm{ii})$ ) is the low-lying structure of the $\mathrm{Al}_{2} \mathrm{Li}_{2}$. This cluster is one of the 
most stable clusters of $\mathrm{Al}_{n} \mathrm{Li}_{n}$. A substantial rise in the binding energy (figure $3 \mathrm{a}$ ) is seen when two Al-Li dimers combine to form $\mathrm{Al}_{2} \mathrm{Li}_{2}$ cluster. Moreover, a peak in the dissociation energy $(\Delta \mathrm{E})$ (figure $3 \mathrm{~b})$, a minima in the second difference in energy $\left(\Delta^{2} \mathrm{E}\right)$ (figure $3 \mathrm{~b}$ ) and a rather large HOMO-LUMO gap (figure 3c) also signifies a relatively high stability of this cluster. Interestingly, the planar $\mathrm{Al}_{2} \mathrm{Li}_{2}$ structure, with some bending, has been observed by Kumar [21] in the magic cluster $\mathrm{Al}_{10} \mathrm{Li}_{8}$. However, because of his restricted nature of search, he did not find this 8 valence electron system to have particular stability.

A similar quinted roof structure is also seen in the ground state structures of the clusters $\mathrm{Al}_{3} \mathrm{Li}_{3}$ and $\mathrm{Al}_{4} \mathrm{Li}_{4}$ (figures $1 \mathrm{~b}(\mathrm{i})$ and $1 \mathrm{c}(\mathrm{i})$ ). However, the $\mathrm{Al}_{3} \mathrm{Li}_{3}$ cluster is not energetically as stable as $\mathrm{Al}_{2} \mathrm{Li}_{2}$, as seen from figures 3a, 3b, and 3c. The lowest energy structure of $\mathrm{Al}_{4} \mathrm{Li}_{4}$ shows two units of $\mathrm{Al}_{2} \mathrm{Li}_{2}$ (figure $1 \mathrm{c}(\mathrm{i})$ ). These two units are arranged so as to form a rectangle out of the four $\mathrm{Al}$ atoms. Indeed, it is this rectangular shape that gives rise to an antiaromatic nature in this cluster $[9,12]$. This structure has been extensively studied by us $[9,11,41]$ and others [12]. The two low-lying structures of $\mathrm{Al}_{4} \mathrm{Li}_{4}$ (figure $1 \mathrm{c}(\mathrm{ii})$ and $1 \mathrm{c}(\mathrm{iii})$ ) show a square-plane and a quinted roof of four Al atoms, respectively.

In $\mathrm{Al}_{5} \mathrm{Li}_{5}$ cluster, a square-plane of $\mathrm{Al}_{4}$ is seen, with the fifth $\mathrm{Al}$ atom capping this plane forming a pyramid (figure 1d). Such a square-planar geometry of $\mathrm{Al}_{4}$ has been observed in the all-metal aromatic compounds $\mathrm{Al}_{4}^{2-}$ and $\mathrm{MAl}_{4}^{-}(M=\mathrm{Li}, \mathrm{Na}$, and $\mathrm{Cu})[8] . \mathrm{Al}_{5} \mathrm{Li}_{5}$ shows the first three dimensional structure of $\mathrm{Al}_{n}$ in $\mathrm{Al}_{n} \mathrm{Li}_{n}$ clusters. Recall that the appearance of such three dimensional geometry in pure $\mathrm{Al}$ clusters [16] is seen for $\mathrm{Al}_{6}$. The $\mathrm{Al}_{5} \mathrm{Li}_{5}$ cluster is the most stable among the clusters studied. This is clear from the binding energy, $\Delta \mathrm{E}$, $\Delta^{2} \mathrm{E}$, and the HOMO-LUMO gap plots shown in figures 3a-3c, respectively. An interesting aspect of the $\mathrm{Al}_{5} \mathrm{Li}_{5}$ cluster is the formation of a plane composed of four Li atoms with one $\mathrm{Al}$ atom at the center, akin to the face of a fcc cell. Similar structure for $\mathrm{Al}_{5} \mathrm{Na}_{5}$ was predicted by Dhavale [18] et al. A complete fcc structure can be formed by fourteen atoms: six $\mathrm{Al}$ atoms at the face centered sites and eight Li atoms at the vertices of the cube. Such a structure was first studied by Shah [28] et al. using DBMD. They found this structure to be the lowest energy structure of $\mathrm{Al}_{6} \mathrm{Li}_{8}$. However, our investigation shows that this fcc 
structure, with slight distortion, is $1.11 \mathrm{eV}$ higher than that the most stable structure. The lowest energy structure and the fcc structure of this cluster is shown in figure 1f(i) and 1f(ii), respectively. It can be noted that these two structures are nearly similar, the main difference being the elongation of one of the $\mathrm{Al}_{4}$ square-planes in the fcc structure into a rectangle. It is interesting to note that the series $\mathrm{Al}_{4}^{2-}, \mathrm{Li}_{-} \mathrm{Al}_{4}^{-}, \mathrm{Al}_{5} \mathrm{Li}_{5}$, and $\mathrm{Al}_{6} \mathrm{Li}_{8}$ shows a three dimensional octahedral growth of $\mathrm{Al}$ cluster surrounded by Li atoms. This results in an effective delocalization of the electron density (see section III B).

The $\mathrm{Al}_{6} \mathrm{Li}_{6}$ cluster also shows a geometry similar to that of $\mathrm{Al}_{5} \mathrm{Li}_{5}$, with distortions in the $\mathrm{Al}_{4}$ square-plane (figure 1e(i)). In the first low energy structure (figure 1e(ii)), a tetrahedra of $\mathrm{Al}_{4}$ is seen, while the other low lying structure (figure 1e(ii)) shows an octahedra of $\mathrm{Al}_{6}$. The octahedral structure is the ground state geometry of pure $\mathrm{Al}_{6}$ cluster [16].

The appearance of a pentagonal ring, which is a precursor to the icosahedral growth, is seen for $n=7\left(\mathrm{Al}_{13}\right.$ is a distorted icosahedron in its ground state [42]). The ground state geometry of $\mathrm{Al}_{7} \mathrm{Li}_{7}$ shows a pentagonal bipyramid which is capped by the Li atoms (figure $2 \mathrm{a}(\mathrm{i})$ ). Appearance of a similar pentagonal ring in pure Al clusters (in neutral as well as singly charged form) is seen for $\mathrm{Al}_{9}[16]$ as well as in tetravalent atom clusters viz. Sn, and $\mathrm{Pb}[27]$ for seven atom clusters. Incidentally, these clusters are isoelectronic to $\mathrm{Al}_{7} \mathrm{Li}_{7}$ with 28 valence electrons. The low energy structure of $\mathrm{Al}_{7} \mathrm{Li}_{7}$ (figure $2 \mathrm{a}(\mathrm{ii})$ ) as well as the ground state geometries of $n=8,9$, and 11 clusters (figure $2 \mathrm{~b}(\mathrm{i}), 2 \mathrm{c}(\mathrm{i})$ and $2 \mathrm{e}(\mathrm{i})$, respectively) also shows such pentagonal rings. However, the lowest energy structure of $\mathrm{Al}_{10} \mathrm{Li}_{10}$ cluster (figure $2 \mathrm{~d}(\mathrm{i})$ ) is completely different from that of the $\mathrm{Al}_{7} \mathrm{Li}_{7}$ to $\mathrm{Al}_{9} \mathrm{Li}_{9}$ and $\mathrm{Al}_{11} \mathrm{Li}_{11}$, in that, no signature of the pentagonal ring is seen. In fact, the geometry is similar to that of $\mathrm{Sn}_{10}$, i.e. a tetracapped trigonal prism (TTP) [43] with some distortions. This TTP structure is enclosed in a Li cage resulting in its distortion. It also shows magical behavior, since it exhibits a peak in the dissociation energy $(\Delta \mathrm{E})$, a minima in the second difference in energy $\left(\Delta^{2} \mathrm{E}\right)$, and a large HOMO-LUMO gap (figure 3a-3c, respectively).

We have performed an analysis of the interatomic bond distances in order to understand the mixing and segregation behavior of the $\mathrm{Al}$ and the Li atoms. In figure $3 \mathrm{~d}$, we plot the 
smallest bond distances of Al-Al, Al-Li and Li-Li as a function of number of $\mathrm{Al}$ atoms in the $\mathrm{Al}_{n} \mathrm{Li}_{n}$ cluster. We find that in smaller clusters $(n \leq 4)$ the Al-Al bond is dominant. However, from $n=5$ onwards, the Al-Li bond distance is comparable to that of Al-Al. Recall that at $n=5$, the first three dimensional $\mathrm{Al}_{n}$ structure emerges, thereby increasing the surface area. This helps the Li atoms to maximize the number of Al-Li bonds and thereby move closer to the $\mathrm{Al}$ atoms.

It is well known that the density based method is not as accurate as the Kohn-Sham method, nonetheless, it has been extensively used to investigate the geometry, and stability of various Al-Li clusters [28-30]. Here, we make some pertinent comments on the difference in the geometry of the $\mathrm{Al}_{n} \mathrm{Li}_{n}$ clusters obtained by these two methods. Our results show that the geometries of some of the clusters were in good agreement with those predicted by DBMD. For instance, the structure of $\mathrm{Al}_{2} \mathrm{Li}_{2}$ was found to be a quinted roof by both the methods (see ref. 28 for DBMD results). The geometries of other clusters like $\mathrm{Al}_{7} \mathrm{Li}_{7}$ to $\mathrm{Al}_{9} \mathrm{Li}_{9}$ show some substitutional disorder. However, there are certain clusters where the geometries were quite different by the KS method. For instance, the structures of, $\mathrm{Al}_{3} \mathrm{Li}_{3}$, predicted by DBMD, is a capped trigonal bipyramid [28]. When optimized by KS, this structure gets Jahn-Teller distorted into a structure with a quinted roof of $\mathrm{Al}_{2} \mathrm{Li}_{2}$. The evolution in the geometry by DBMD method shows an earlier appearance of three dimensional structure of $\mathrm{Al}_{n}$ at $n=4\left(\mathrm{Al}_{4}\right.$ is tetrahedra in $\left.\mathrm{Al}_{4} \mathrm{Li}_{4}\right)$, as compared to the pyramidal structure of $\mathrm{Al}_{5}$ in $\mathrm{Al}_{5} \mathrm{Li}_{5}$ by KS method.

\section{B. Bonding}

\section{1. $A l_{2} L i_{2}$}

As noted above, $\mathrm{Al}_{2} \mathrm{Li}_{2}$ is one of the most stable cluster. This cluster has 8 valence electrons, which corresponds to a closed shell in the jellium sense. However, the behavior of the MOs as well as the eigenvalue spectrum does not resemble to that of the SJM. 
Kumar [21] found that the bonding between $\mathrm{Al}-\mathrm{Li}$ in the planar $\mathrm{Al}_{2} \mathrm{Li}_{2}$ structure is ionic. On the contrary, our investigation on the bent rhombus structure does not show signature of any significant charge transfer from the Li atoms to the $\mathrm{Al}$ atoms. However, an analysis of the difference charge density shows that, a charge transfer from the Li atoms to the bonding region between the $\mathrm{Al}$ and Li atoms takes place (figure not shown). In order to get better insight of the bonding in $\mathrm{Al}_{2} \mathrm{Li}_{2}$, we have studied various clusters viz. $\mathrm{Al}_{2}, \mathrm{Al}_{2}^{-}, \mathrm{Al}_{2}^{2-}$, $\mathrm{Al}_{2} \mathrm{Li}, \mathrm{Al}_{2} \mathrm{Li}^{-}$, and $\mathrm{Al}_{2} \mathrm{Li}_{2}$. This series represent a growth of $\mathrm{Al}_{2} \mathrm{Li}_{2}$ from the $\mathrm{Al}_{2}$ dimer. In figure 4, we show the eigenvalue spectrum, and the Al-Al bond distance for the optimized geometries of these clusters. The eigenvalue spectrum of $\mathrm{Al}_{2}$ (figure 4a), in neutral, singly and doubly charged form, shows a triply degenerate HOMO state. These states are partially filled two $\pi$ and one $\sigma$ bond (figure not shown). Successive substitution of each electron in the charged dimer, by Li atoms splits the HOMO state reducing the degeneracy. The first Li atom forms a $\sigma$ bond with the $p_{y}-p_{y} \pi$ orbital of the $\mathrm{Al}_{2}$ dimer (isodensity surfaces not shown). The second Li atom further splits the HOMO state introducing a substantial gap of $0.68 \mathrm{eV}$. However, in this case, a hybridization of the $s$ orbital of Li atom and the $\pi$ orbital of $\mathrm{Al}_{2}$ takes place. In figure 5, we show the second $\mathrm{HOMO}$ and the HOMO state of the $\mathrm{Al}_{2} \mathrm{Li}_{2}$ cluster. Clearly, these states shows the $\pi$ bonded orbitals of $\mathrm{Al}_{2}$ hybridized with the $s$ orbitals of the Li atoms. In figure $4 \mathrm{~b}$, we plot the $\mathrm{Al}-\mathrm{Al}$ bond distance in these clusters. A contraction of the Al-Al bond upon addition of an electron or a $\mathrm{Li}$ atom is seen. The contraction of the bond on addition of a Li atom being more than that due to the addition of an electron. Thus, the hybridization of the $s$ orbitals of Li with the $\pi$ orbitals of $\mathrm{Al}_{2}$ enhances its stability.

\section{2. $\mathrm{Al}_{4} \mathrm{Li}_{4}$}

The bonding in $\mathrm{Al}_{4} \mathrm{Li}_{4}$ cluster has been extensively studied by us $[9,11,41]$ and others [12]. This cluster has been found to be antiaromatic with four $\pi$-electrons. For the sake of completeness, we discuss the bonding in this cluster. This cluster, as discussed ear- 
lier, is composed of two $\mathrm{Al}_{2} \mathrm{Li}_{2}$ units arranged edge-to-edge to form a $\mathrm{Al}_{4}$ rectangle. This rectangular structure leads to antiaromaticity. In this cluster $s p^{2}$ hybridization of $\mathrm{Al}$ takes place leaving one empty unhybridized $p$ orbital. The valence electron of each of the four $\mathrm{Li}$ atoms is then transfered to this empty $p_{z}$ orbital, thus providing four $\pi$-electrons for antiaromaticity. Interestingly, its first low-lying structure (figure 1c(ii)) can also be considered as a candidate for antiaromaticity. An analysis of the MOs shows that this cluster also has four $\pi$-electrons similar to that of the lowest energy structure, thereby conforming the structural and electron count criteria for antiaromaticity. However, a detailed analysis of the magnetic field induced ring currents has to be done in order to understand the antiaromaticity in this structure.

\section{3. $A l_{5} \mathrm{Li}_{5}$ and $A l_{6} \mathrm{Li}_{8}$}

As discussed in section IIIA, the structures of $\mathrm{Al}_{5} \mathrm{Li}_{5}$ and $\mathrm{Al}_{6} \mathrm{Li}_{8}$ (in fcc geometry) clusters show a square-plane of $\mathrm{Al}_{4}$. Such $\mathrm{Al}_{4}$ square-plane in $\mathrm{Al}_{4}^{2-}$ and $\mathrm{Li}-\mathrm{Al}_{4}^{-}$has lead to aromaticity in these clusters [8]. Moreover, these clusters $\left(\mathrm{Al}_{4}^{2-}, \mathrm{Li}-\mathrm{Al}_{4}^{-}, \mathrm{Al}_{5} \mathrm{Li}_{5}\right.$, and $\left.\mathrm{Al}_{6} \mathrm{Li}_{8}\right)$ show a three dimensional octahedral growth of the Al cluster. It is, therefore, interesting to discuss the change in bonding, and hence the effect on aromaticity in these clusters. Recall that $\mathrm{Al}_{4}^{2-}$ and $\mathrm{Li}-\mathrm{Al}_{4}^{-}$are aromatic clusters with two $\pi$-electrons [8]. The HOMO state in these clusters are completely delocalized $\pi$ orbitals. There are two more delocalized $\sigma$ bonds: one composed of radial $p$ orbitals, and the other composed of perpendicular $p$ orbitals. Due to the presence of a $\mathrm{Al}_{4}$ square-plane, the bonding in $\mathrm{Al}_{5} \mathrm{Li}_{5}$ and $\mathrm{Al}_{6} \mathrm{Li}_{8}$ clusters is expected to be similar to that in $\mathrm{Al}_{4}^{2-}$. In that case, these clusters would have two $\pi$-electrons similar

to that of $\mathrm{Al}_{4}^{2-}$ and $\mathrm{Li}_{-} \mathrm{Al}_{4}^{-}$, and show some signature of aromaticity. In figure 7a and 7b, we show the $\mathrm{HOMO}$ states of $\mathrm{Al}_{5} \mathrm{Li}_{5}$ and $\mathrm{Al}_{6} \mathrm{Li}_{8}$. Interestingly, the $\mathrm{HOMO}$ state of $\mathrm{Al}_{5} \mathrm{Li}_{5}$ does show such a delocalized $\pi$ bond between the $\mathrm{Al}_{4}$ square (figure $7 \mathrm{a}$ ). However, a lone electron is seen at the fifth $\mathrm{Al}$ atom that caps this square. This reduces the number of $\pi$ electrons count to one, thereby losing the aromaticity. The HOMO state of $\mathrm{Al}_{6} \mathrm{Li}_{8}$, on the other hand, 
is quite different than that seen in the previous clusters (see figure 7b). It shows a localized bond composed of $p$ orbitals of the $\mathrm{Al}$ atoms. In figure 6, we show the eigenvalue spectrum of $\mathrm{Al}_{6} \mathrm{Li}_{8}$, along with that of the other $\mathrm{Al}_{n} \mathrm{Li}_{n}(n=1-11)$ and $\mathrm{Sn}_{10}$ clusters. It is clear from this that the eigenvalue spectrum of $\mathrm{Al}_{6} \mathrm{Li}_{8}$ shows nearly a jellium-like structure. However, an analysis of the behavior of the molecular orbitals (figure not shown) of $\mathrm{Al}_{6} \mathrm{Li}_{8}$ shows that the lower six states are jellium-like, whereas, the higher states show localized bonds arising out of $p$ orbitals of the $\mathrm{Al}$ atoms. The isodensity surfaces for the $6^{\text {th }}$ state of $\mathrm{Al}_{5} \mathrm{Li}_{5}$ and the $10^{\text {th }}$ state of $\mathrm{Al}_{6} \mathrm{Li}_{8}$ are shown in figure $7 \mathrm{c}$, and $7 \mathrm{~d}$, respectively. These are $\sigma$-bonded states, composed of radial $p$ orbitals and are analogous to the radial $p$ orbitals of $\mathrm{Al}_{4}^{2-}$, as noted by Wang et al [8]. Since, these bonds involve all the Al atoms, they exhibit a substantial delocalization.

$$
\text { 4. } A l_{n} L i_{n}(n=7-11)
$$

The bonding in these clusters $\left(\mathrm{Al}_{n} \mathrm{Li}_{n}, n=7-11\right)$, is quite different from that of the smaller clusters. The analysis of the behavior of the MOs shows that the eigenvalue spectrum can be classified into two groups: the lower $n$ states are jellium-like, whereas, the higher states forms a complex band of localized bonds arising out of the interaction of the $p$ electrons of each of the $\mathrm{Al}$ atoms. The lower states can be identified as $1 s, 1 p, 1 d, 2 s, \ldots$, in conformation to the SJM. Typical representative isodensity plots of these states are shown in figure 8 . They represent the $1 s, 1 p, 1 d$ and $2 s$ states of the jellium composed of the Al-3s orbitals. In figure 6 , we show the eigenvalue spectrum of $\mathrm{Al}_{n} \mathrm{Li}_{n}(n=1-11)$ and $\mathrm{Sn}_{10}$ clusters. This figure shows a clear energy separation of lower jellium-like $n$ states of the clusters with $n>6$, from the higher orbitals. In order to study this more extensively, we have performed a spherical harmonics analysis of the KS orbitals [44]. We find that the lower $n$ orbitals have a predominant $s$ character $(75-85 \%)$ indicating that these state are arising out of the $3 s$ orbitals of the $\mathrm{Al}$ atoms, which hybridizes to form a jellium. However, this description cannot be extended to the higher states. The higher states are composed of Al-3p orbitals. 
The localization characteristics in the bonding in the Al-Li clusters is also analyzed via the electron localization function plots. Previous investigations show that even in large Al-Li clusters, the Al-Al bond is covalent. However, our earlier work on the structural properties shows a clustering of $\mathrm{Al}$ atoms enclosed in Li cage. This clustering could lead to a delocalization of the electron density. In order to study this, we have analyzed the electron localization function in the $\mathrm{Al}_{n} \mathrm{Li}_{n}$ clusters. In figure 9, we show the isovalued surface of the ELF for the clusters $\mathrm{Al}_{2} \mathrm{Li}_{2}, \mathrm{Al}_{5} \mathrm{Li}_{5}$, and $\mathrm{Al}_{10} \mathrm{Li}_{10}$, at the values $0.85,0.8$, and 0.72 , respectively. These plots shows a localization of the electron density along the Al-Al bond (increasing the value of ELFs does not show any bond between Al-Al). It has been noted by Silvi et al [31], that an ELF value of about 0.7 or greater is a indication of a localized bond in that region. Thus, the Al-Al bonds in these clusters are predominantly covalent, in accordance with the previous observation. However, as the cluster grows in size, the degree of localization of the electron density in these clusters is reduced. Further, the localization in $\mathrm{Al}_{5} \mathrm{Li}_{5}$ is only in the plane forming the square (for out of plane, the $\mathrm{Al}-\mathrm{Al}$ bond is seen for the ELF value of 0.7 ). A similar behavior of the ELF for $\mathrm{Al}_{7} \mathrm{Li}_{7}$ (not shown in figure) is seen, in that, a localized bond along the pentagon $(\mathrm{ELF}$ value $=0.78)$ and delocalized bond in the perpendicular direction $(\mathrm{ELF}$ value $=0.6)$ is seen.

\section{TETRAVALENT BEHAVIOR OF Al IN Al $\mathrm{l}_{n} \mathrm{Li}_{n}$ CLUSTERS}

Previous investigations on mixed Al-Li clusters $[21,45,46]$, have shown a substantial

charge transfer from the $\mathrm{Li}$ atom to the Al atom. Due to such charge transfer, Al behaves as a tetravalent atom in mixed Al-Li clusters with nearly 50:50 percent concentration. In this section, we present the evidence of such behavior. The analysis of the geometries of $\mathrm{Al}_{n}$ in $\mathrm{Al}_{n} \mathrm{Li}_{n}$ shows remarkable similarities to those of the clusters of the tetravalent atoms viz., Si, Ge, Sn and $\mathrm{Pb}$. The transition from planar to three dimensional geometry at $n=5$, the appearance of a pentagonal ring at $n=7$, and the formation of the distorted TTP structure of 10 atom cluster are some of the features of the clusters of tetravalent 
atoms. Such behavior of $\mathrm{Al}_{n}$ in $\mathrm{Al}_{n} \mathrm{Li}_{n}$ clusters is also observed. Moreover, the eigenvalue spectrum, in figure 6 , of the $\mathrm{Al}_{10} \mathrm{Li}_{10}$ show remarkable similarity to that of the $\mathrm{Sn}_{10}$ cluster. The bonding between $\mathrm{Al}-\mathrm{Al}$ in these clusters is covalent, which is similar to that in the clusters of tetravalent atoms. Finally, the resemblance of the DOS of the Al-Li in its most stable bulk phase i.e. B32, to that of diamond [24] also indicates a tetravalent behavior of the $\mathrm{Al}$ atom in Al-Li systems with 50:50 concentration.

\section{CONCLUSION}

In the present work, we have reported the systematic investigation of the geometries, energetics, electronic structure and bonding in various $\mathrm{Al}-\mathrm{Li}$ clusters viz. $\mathrm{Al}_{n} \mathrm{Li}_{n}(n=1$ 11), $\mathrm{Al}_{2}^{-}, \mathrm{Al}_{2}^{2-}, \mathrm{Al}_{2} \mathrm{Li}, \mathrm{Al}_{2} \mathrm{Li}^{-}$, and $\mathrm{Al}_{6} \mathrm{Li}_{8}$ using $\mathrm{BOMD}$ within the framework of density functional theory. The bonding in these clusters was discussed via the electron localization function as well as the behavior of the molecular orbitals. The growth pattern is divided into two broad categories: first consisting of a bent rhombus of $\mathrm{Al}_{2} \mathrm{Li}_{2}(n=2-4)$ and second consisting of a pentagonal ring $(n=7-9,11)$. We find that the 8,20 , and 40 valence electron systems to be magic, exhibiting a peak in the dissociation energy, a minima in the second difference in energy, and a large HOMO-LUMO gap. The structural transition of $\mathrm{Al}_{n}$ in $\mathrm{Al}_{n} \mathrm{Li}_{n}$, from two dimension to three dimension increases the surface area, thereby helping the $\mathrm{Li}$ atoms to maximize the number of $\mathrm{Al}-\mathrm{Li}$ bonds, as a result of which the $\mathrm{Li}$ atoms move closer to the $\mathrm{Al}$ atoms. In clusters with more than six $\mathrm{Al}$ atoms, a charge transfer from $\mathrm{Li}$ atoms to $\mathrm{Al}$ atoms makes $\mathrm{Al}$ behave as a tetravalent atom like $\mathrm{Si}, \mathrm{Ge}, \mathrm{Sn}$, and $\mathrm{Pb}$ in $\mathrm{Al}_{n} \mathrm{Li}_{n}$ clusters. These negatively charged $\mathrm{Al}_{n}$ structure is then stabilized by the positive Li environment. The behavior of the MOs in these clusters $(n>6)$ can be divided two groups: a lower group of jellium-like states arising out of the $s$ electrons of the Al atoms and a higher group of localized bonds formed through the interaction of the $p$ electrons on each of the $\mathrm{Al}$ atoms. The formation of the three dimensional $\mathrm{Al}_{n}$ structure destroys the aromatic and antiaromatic nature in these clusters. 


\section{ACKNOWLEDGEMENT}

SC gratefully acknowledges the financial support of CSIR (New Delhi). VVP wishes to thank NSERC of Canada and the University of Pune for partially supporting this research. 


\section{REFERENCES}

$\dagger$ chacko@physics.unipune.ernet.in

$\ddagger$ kanhere@unipune.ernet.in

[1] H.W. Kroto, J.R. Heath, S.C. O'Brian, R.F. Curl, and R.E. Smalley, Nature (London) 318, 162 (1985).

[2] W.D. Knight, K. Clemenger, W.A. de Heer, W.A. Saunders, M.Y. Chou, and M.I. Cohen, Phys. Rev. Lett. 52, 2141 (1984).

[3] M. Schmidt, R. Kushe, W. Kronmüller, B. von Issendorff, and H. Haberland, Nature (London) 393, 238 (1998); ibid Phys. Rev. Lett. 79, 99 (1997).

[4] A.A. Shvartsburg, and M.F. Jarrold, Phys. Rev. Lett. 85, 2530 (2000).

[5] Advances in Cluster Science, Vijay Kumar, K. Esfarjini, and Y. Kawazoe, SpringerVerlag, Heidelberg, 2000. Theory of Atomic and Molecular Clusters with a Glimpse at Experiments,

edited by J. Jellinek, Springer Series in Cluster Physics (Springer, Berlin, 1999). Physics and Chemistry of Finite Systems: From Clusters to Crystals, edited by P. Jena, S.N. Khanna, and B.K. Rao (Kluwer Academic, Dordrecht, The Netherlands, 1992);

[6] Clusters and Nanostructured Materials, P. Jena, and S.N. Behera, Nova Science Publishers, Inc., New York, (1996).

[7] Reviews of Modern Quantum Chemistry, Volume I and II, edited by K.D. Sen, World Scientific, Singapore, 2002.

[8] Xi Li, Aleksey E. Kuznetsov, Hai-Feng Zhang, Alexander I, Boldyrev, Lai-Sheng Wang, Science, 291, 859 (2001); Xi Li, Hai-Feng Zhang, Lai-Sheng Wang, Aleksey E. Kuznetsov, Nathan A. Cannon, and Alexander I, Boldyrev, Angewandte Chemie, International Edition, 40, 1867 (2001); 
[9] The antiaromatic properties in $\mathrm{Al}_{4} \mathrm{Li}_{4}$ was presented in the Abstract in the Symposium on Trends in Theoretical Chemistry-2002 (TTC-2002), January 17-19, 2003 Indian Association for the cultivation of science Kolkata,

[10] S. Shetty, D.G. Kanhere, and S. Pal, communicated to J. Phys. Chem. B (2003).

[11] Remco W.A. Havenith, Patrick W. Fowler, Erich Steiner, Sharan Shetty, Dilip Kanhere and Sourav Pal, unpublished.

[12] Aleksey E. Kuznetsov, K. Alexander Birch, Alexander I. Boldyrev, Xi Li, Hua-Jin Zhai, Lai-Sheng Wang, Science, 300, 622 (2003).

[13] Molecules that are cyclic, planar, conjugated, possessing $(4 n+2) \pi$ electrons and having chemical and structural stability are called as aromatic molecules. For details see the special issue on Aromaticity, Chem. Rev. 101 (no. 5) (2001).

[14] R. Breslow, and W. Chu, J. Am. Chem. Soc. 92, 2165 (1970); R. Breslow Acc. Chem. Res. 6, 393 (1973).

[15] I. Boustani, W. Pewerstorf, P. Fantucci, V. Bonačić-Koutecký, and J. Koutecký, Phys. Rev. B 35, 9437 (1987).

[16] B.K. Rao, and P. Jena, J. Chem. Phys. 111, 1890 (1999).

[17] B.K. Rao, and P. Jena, J. Chem. Phys. 113, 1508 (2000).

[18] Ajeeta Dhavale, D.G. Kanhere, S.A. Blundell, and R. Zope, Phys. Rev. B. 65, 085402 (2002).

[19] Hai-Ping Cheng, R.N. Barnett, and Uzi Landman, Phys. Rev. B 48, 1820 (1993).

[20] Jaakko Akola, and Matti Manninen, Phys. Rev. B 65, 245424 (2002).

[21] Vijay Kumar Phys. Rev. B. 60, 2916 (1999).

[22] X. Li, H. Wu, X.-B. Wang, and L.-S. Wang, Phys. Rev. Lett. 81, 1909 (1998). 
[23] X. -Q. Guo, R. Podloucky, and A.J. Freeman, Phys. Rev. B 40, 2793 (1989); ibid Phys. Rev. B. 42, 10912 (1990).

[24] A. Arya, G.P. Das, H.G. Salunke, S. Banerjee, J. Phys.: Condens. Matter 6, 3389 (1994).

[25] D. Tomanek, M.A. Schlüter, Phys. Rev. Lett., 56, 1055 (1986); P. Ballone, W. Andreoni, R. Car, and M. Parrinello, Phys. Rev. Lett., 60, 271 (1988); K. Raghavchari, and C.M. Rohlfing, J. Chem. Phys., 89, 2219 (1988); I. Vasiliev, S. Ögüt, and J.R. Chelikowsky, Phys. Rev. Lett., 78, 4805 (1997).

[26] S. Ögüt, and J.R. Chelikowsky; Phys. Rev. Lett., 56, 2656 (1986).

[27] Bing Wang, L.M. Molina, M.J. Lo'pez, A. Rubio, J.A. Alonso, and M.J. Stott, Ann. Physik 7, 107-119 (1998).

[28] Vaishali Shah, D.G. Kanhere, Chiranjib Majumder, and G. P. Das, J. Phys.: Condens. Matter 9, 2165-2177 (1997).

[29] V. Shah, and D.G. Kanhere, J. Phys.: Condens. Matter 8, L253 (1997).

[30] A.M. Vichare, and D.G. Kanhere, Eur. Phys. J. D. 4, 89-94 (1998).

[31] B. Silvi, and A. Savin, Nature (London), 371, 683 (1994).

[32] M.C. Payne, M.P. Teter, D.C. Allan, T.A. Arias, and J.D. Joannopoulos, Rev. Mod. Phys. 64, 1045 (1992).

[33] W. Kohn, and L.J. Sham, Phys. Rev. 140, A1133 (1965).

[34] M.C. Payne, J.D. Joannopoulos, D.C. Allan, M.P. Teter, and D.H. Vanderbilt, Phys. Rev. Lett., 56, 2656 (1986).

[35] G.B. Bachelet, D.R. Hamann, and M. Schlüter, Phys. Rev. B 26, 4199 (1982).

[36] L. Kleinman, and D.M. Bylander, Phys. Rev. Lett. 48, 1425 (1982). 
[37] D.M. Ceperley, and B.J. Alder, Phys. Rev. Lett. 45, 566 (1980); J.P. Perdew, and A. Zunger, Phys. Rev. B 23, 5048 (1981).

[38] D. Vanderbilt, Phys. Rev. B 41, 7892 (1990).

[39] Vienna Ab initio Simulation Package (VASP), Technishe Universität, Wien, 1999.

[40] J.P. Perdew, and Wang, J. Chem. Phys. 45, 13244 (1992).

[41] S. Chacko, M. Deshpande, and D.G. Kanhere, Phys. Rev. B 64, 115409 (2001).

[42] U. Röthlishberger, W. Andreoni, and P. Giannozzi, J. Chem. Phys., 96, 1248 (1992).

[43] Kavita Joshi, D.G. Kanhere, and S.A. Blundell, Phys. Rev. B 66, 155329 (2002).

[44] The character in an orbitals is calculated by projecting the orbitals onto spherical harmonics centered at each ionic sites within a sphere of a specified radius around each ion. The radius of the sphere is taken to be half of the distance of the ion from the nearest ion.

[45] X.G. Gong, and V. Kumar, Phys. Rev. Lett. 70, 2078 (1993).

[46] X.G. Gong, and V. Kumar, Phys. Rev. B 50, 17701 (1994). 


\section{List of Figures}

1 The ground state and the low-lying geometries of the $\mathrm{Al}_{n} \mathrm{Li}_{n}(n=2-6)$ and $\mathrm{Al}_{6} \mathrm{Li}_{8}$ clusters. The black circles represent $\mathrm{Al}$ atoms and the white circles represent the $\mathrm{Li}$ atoms. The lowest energy structure is represented by (i).

2 The ground state and the low-lying geometries of the $\mathrm{Al}_{n} \mathrm{Li}_{n}(n=7-11)$ clusters. The black circle represents $\mathrm{Al}$ atoms and the white circles represent the $\mathrm{Li}$ atoms. The lowest energy structure is represented by (i).

3 (a) The binding energy per atom (in eV/atom) of the $\mathrm{Al}_{n} \mathrm{Li}_{n}$ cluster ( $n=1-11$ ). (b) The dissociation energy $(\Delta E)$ and the second difference in the total energy $\left(\Delta^{2} E\right)$ of the $\mathrm{Al}_{n} \mathrm{Li}_{n}$ clusters $(n=2-10)$ with respect to a Al-Li dimer. (c) The HOMO-LUMO gap (in $\mathrm{eV}$ ) of the $\mathrm{Al}_{n} \mathrm{Li}_{n}$ cluster ( $\left.n=1-11\right)$. (d) The minimum interatomic distance $\mathrm{Al}-\mathrm{Al}$, Al-Li and Li-Li (in $\AA$ ) of the $\mathrm{Al}_{n} \mathrm{Li}_{n}$ cluster $(n=1-11)$.

4 (a) The eigenvalue spectrum (in $\mathrm{eV}$ ). The continuous lines correspond to occupied states and dashed lines correspond to the empty states. The numbers on the right indicate the degeneracy of the states. The numbers on the left indicate the occupancies of the states. All other occupied states have two electrons. (b) The Al-Al bond distance (in $\AA$ ).

5 The isodensity surface of the second $\mathrm{HOMO}$ and the $\mathrm{HOMO}$ state of $\mathrm{Al}_{2} \mathrm{Li}_{2}$ at $1 / 5^{\text {th }}$ of its maximum value. The black circles represent $\mathrm{Al}$ atoms and the gray circles represent the Li atoms.

6 The eigenvalue spectrum (in $\mathrm{eV}$ ) of $\mathrm{Al}_{n} \mathrm{Li}_{n}(n=1-11), \mathrm{Al}_{6} \mathrm{Li}_{8}$, and $\mathrm{Sn}_{10}$ clusters. The continuous lines correspond to the occupied states and the dotted lines correspond to the empty states. The numbers on right indicate the degeneracy of the states. All states are doubly occupied. The thick dashed line shows the $n^{\text {th }}$ state of these clusters, where $n$ is the number of $\mathrm{Al}$ atoms. For $\mathrm{Sn}_{10}$ the thick dashed line corresponds to the $10^{\text {th }}$ state. 
7 (a) The isodensity surface of the HOMO state of $\mathrm{Al}_{5} \mathrm{Li}_{5}$, at $1 / 5^{\text {th }}$ of its maximum. (b) The isodensity surface of the HOMO state of $\mathrm{Al}_{6} \mathrm{Li}_{8}$, at $1 / 5^{\text {th }}$ of its maximum. (c) The isodensity surface of the $6^{\text {th }}$ state of $\mathrm{Al}_{5} \mathrm{Li}_{5}$, at $1 / 5^{\text {th }}$ of its maximum. (d) The isodensity surface of the $10^{\text {th }}$ state of $\mathrm{Al}_{6} \mathrm{Li}_{8}$, at $1 / 8^{\text {th }}$ of its maximum. In all the figures, the black circles represent $\mathrm{Al}$ atoms and the gray circles represent the $\mathrm{Li}$ atoms.

8 The isodensity surface of various orbitals. These are: (a) $1^{\text {st }}$ orbital of $\mathrm{Al}_{7} \mathrm{Li}_{7}$ at $1 / 5^{\text {th }}$ of its maximum value, (b) $3^{\text {rd }}$ orbital of $\mathrm{Al}_{8} \mathrm{Li}_{8}$ at $1 / 5^{\text {th }}$ of its maximum value, (c) $8^{\text {th }}$ orbital of $\mathrm{Al}_{9} \mathrm{Li}_{9}$ at $1 / 10^{\text {th }}$ of its maximum value, and (d) $10^{\text {th }}$ orbital of $\mathrm{Al}_{10} \mathrm{Li}_{10}$ at $1 / 5^{\text {th }}$ of its maximum value, representing the $1 s, 1 p, 1 d$, and $2 s$ state of the jellium composed of the Al-3s orbital. In all the figures, the black circles represent $\mathrm{Al}$ atoms and the gray circles represent the Li atoms.

9 The isodensity surface of the electron localization function (ELF) of: (a) $\mathrm{Al}_{2} \mathrm{Li}_{2}$ at the value 0.85 , (b) $\mathrm{Al}_{5} \mathrm{Li}_{5}$ at the value 0.80 , and (c) $\mathrm{Al}_{10} \mathrm{Li}_{10}$ at the value 0.72 . In all the figures, the black circles represent $\mathrm{Al}$ atoms and the gray circles represent the $\mathrm{Li}$ atoms. 
FIGURES 


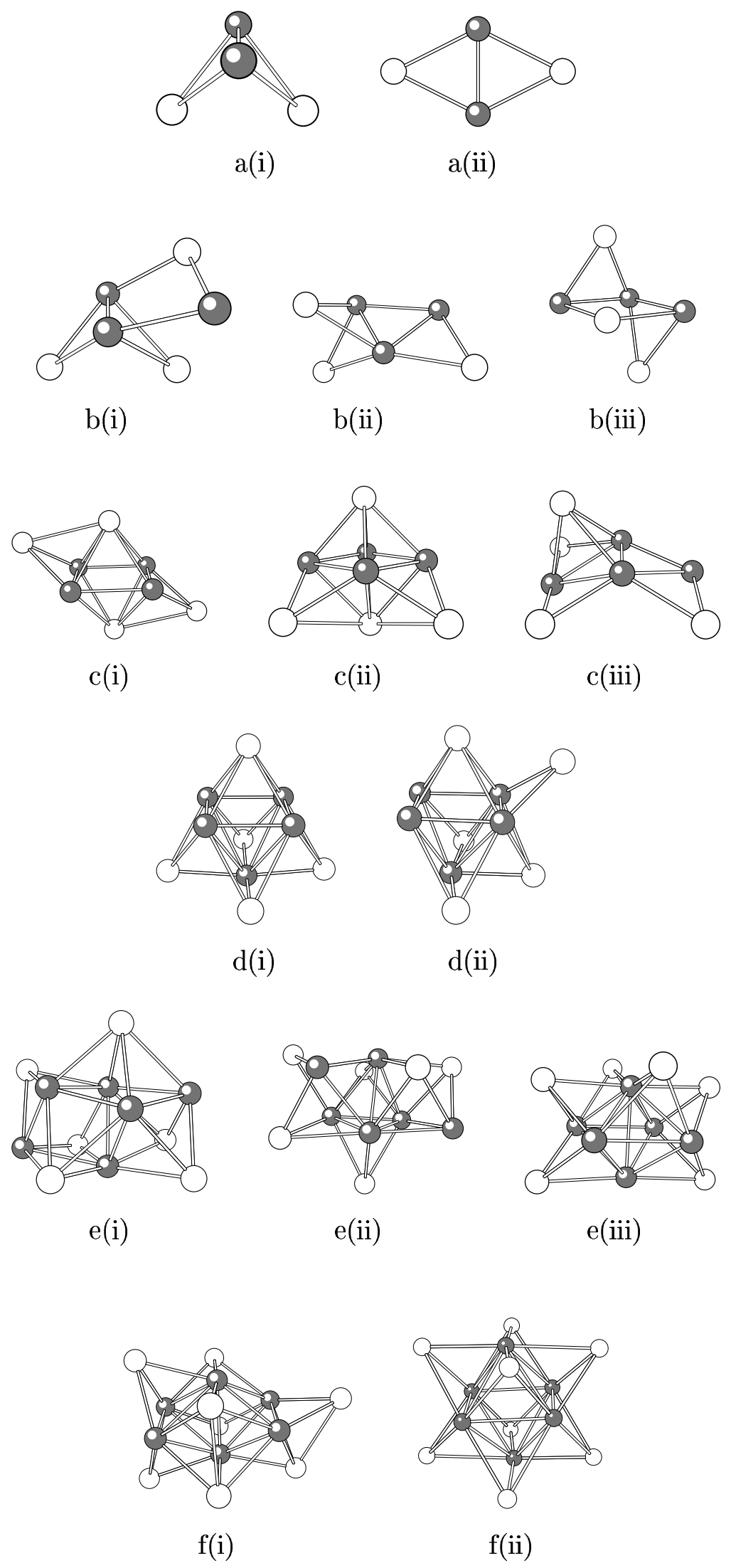

FIG. 1. 


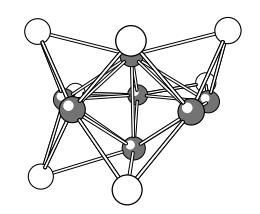

a(i)

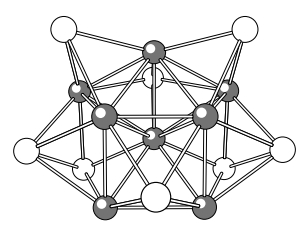

b(i)

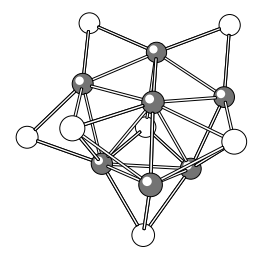

a(ii)

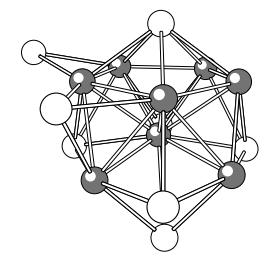

b(ii)

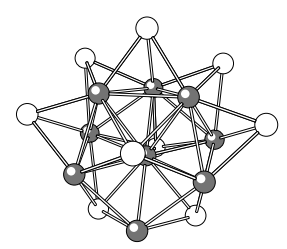

c(i)

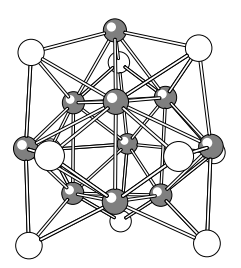

d(i)

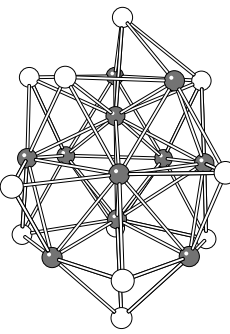

e(i)

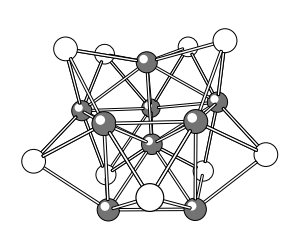

c(ii)

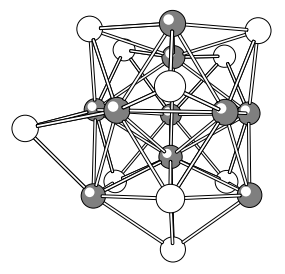

d(ii)

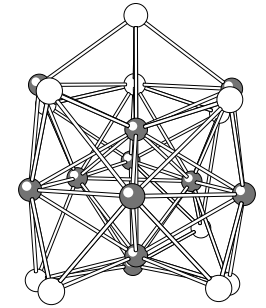

e(ii)

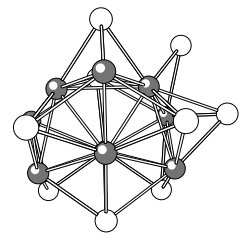

c(iii)

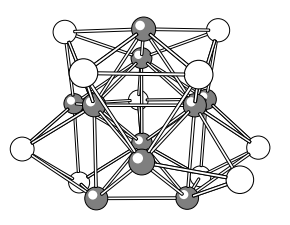

d(iii)

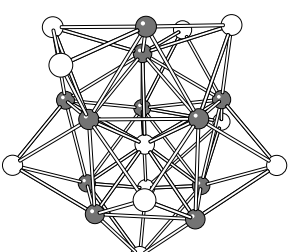

e(iii)

FIG. 2. 

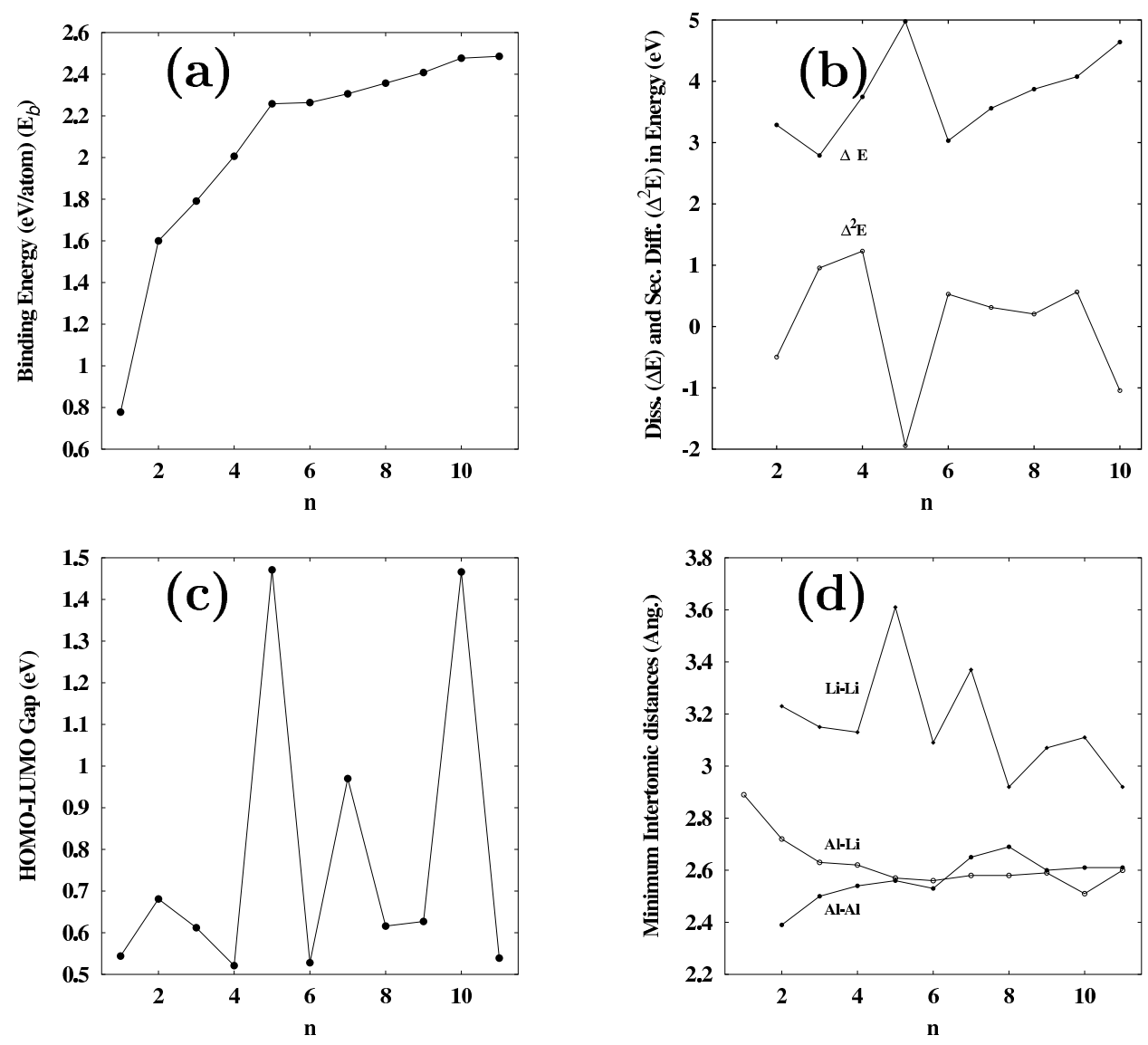

FIG. 3. 

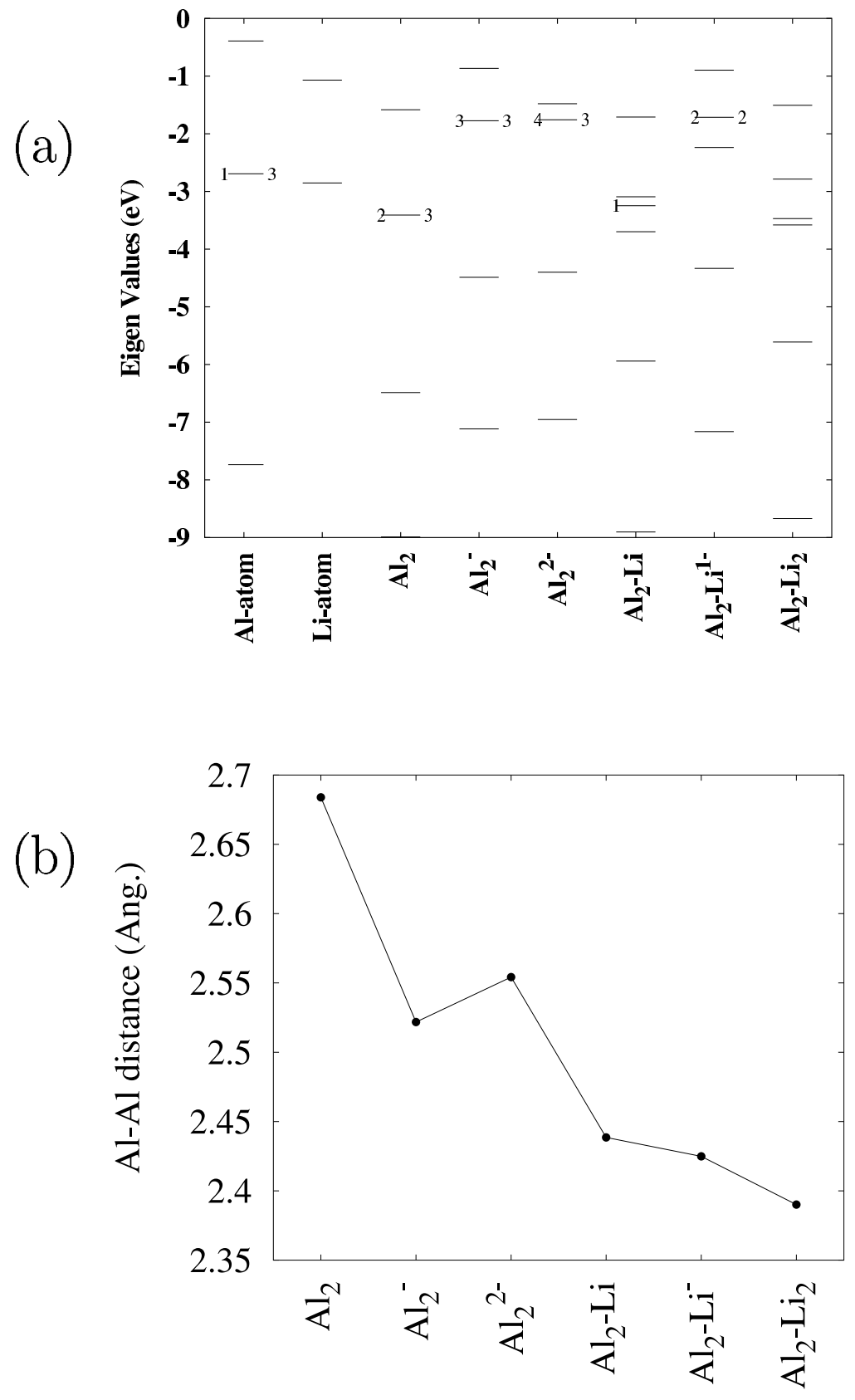

FIG. 4. 


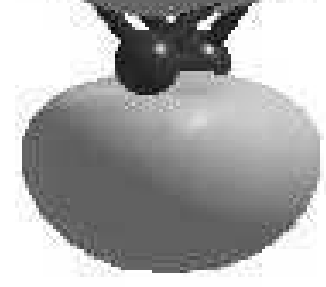

(a)

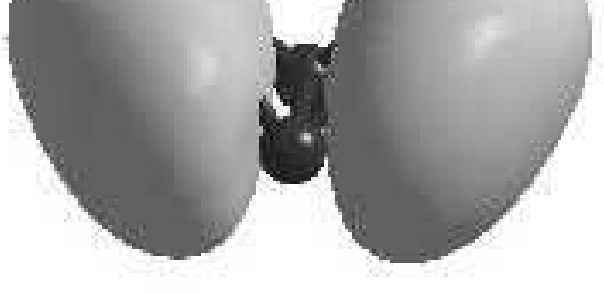

(b)

FIC. 5.

FIG. 5. 


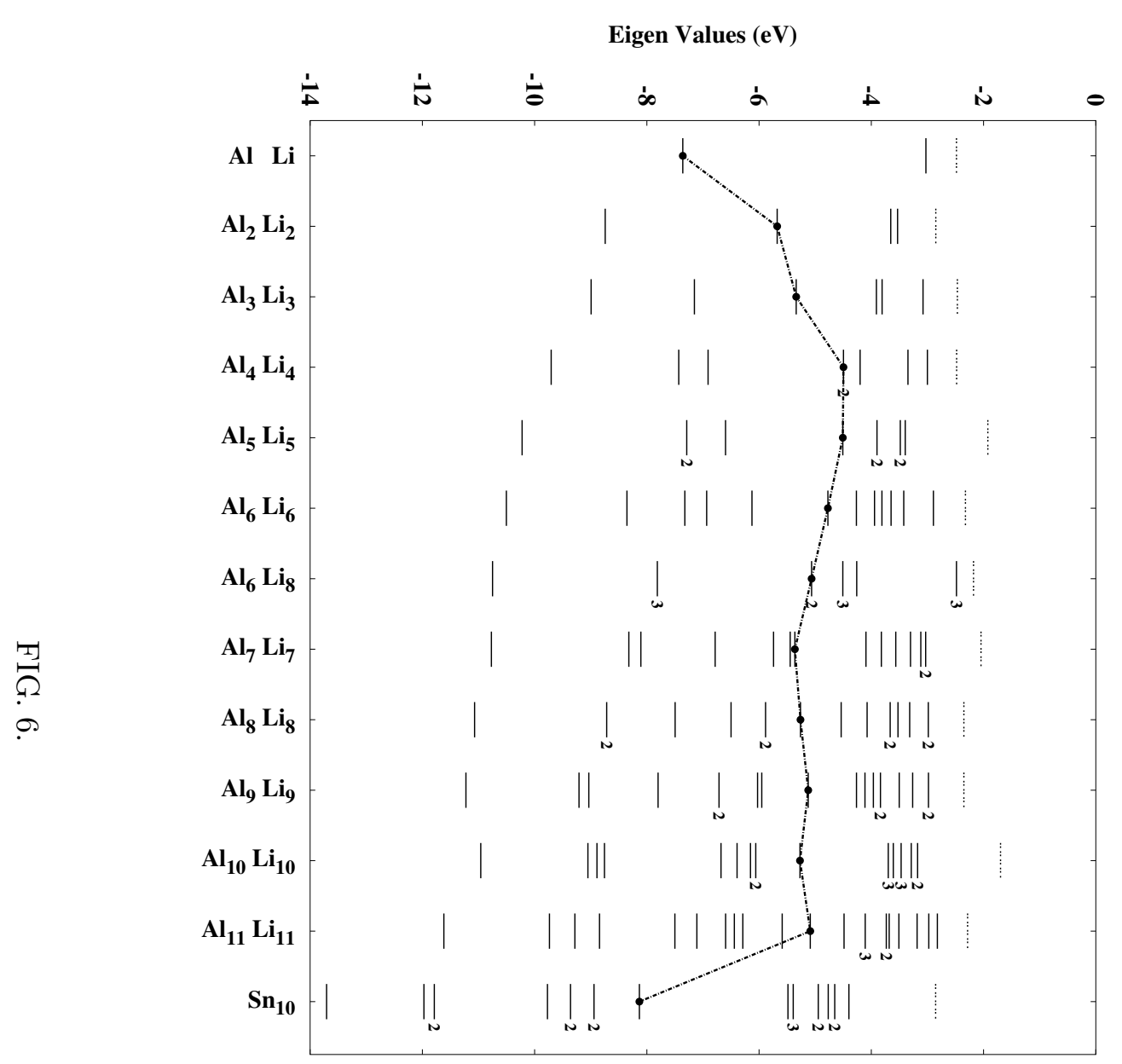




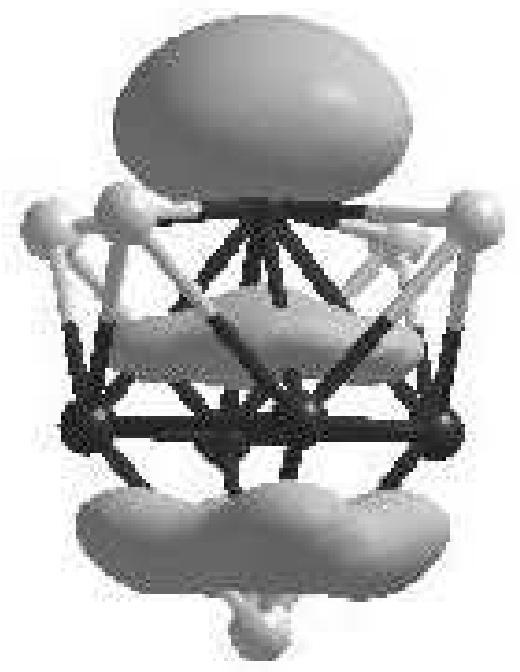

01

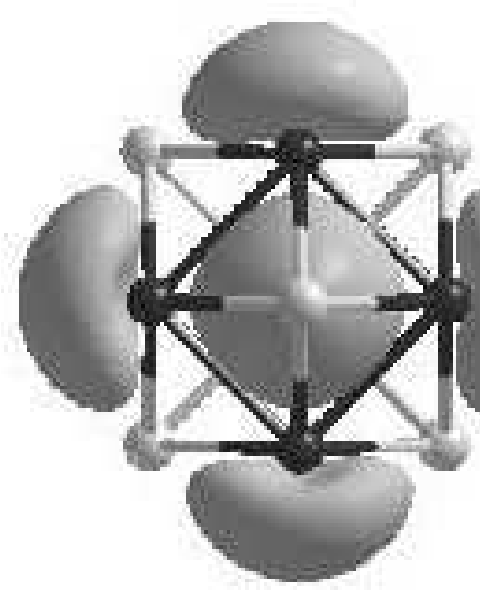

i:

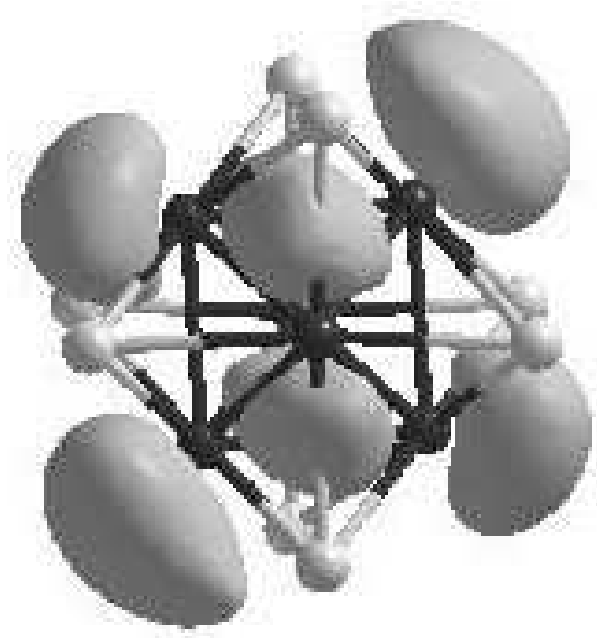

(1)

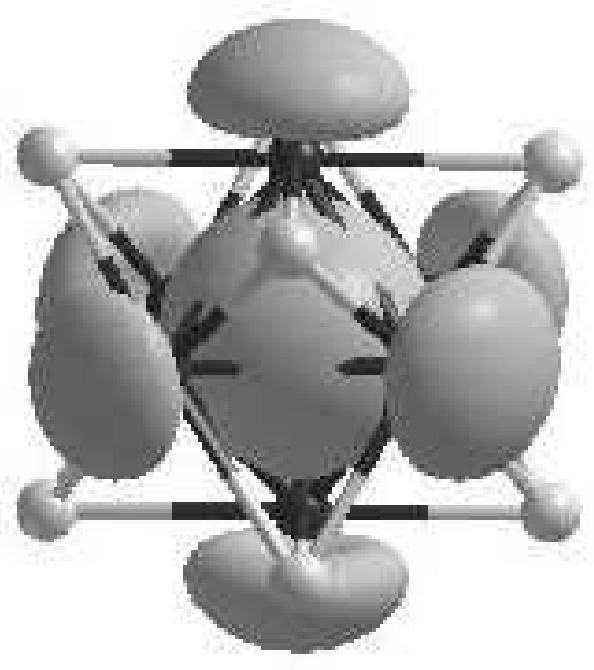

6

FIG $?$.

FIG. 7. 


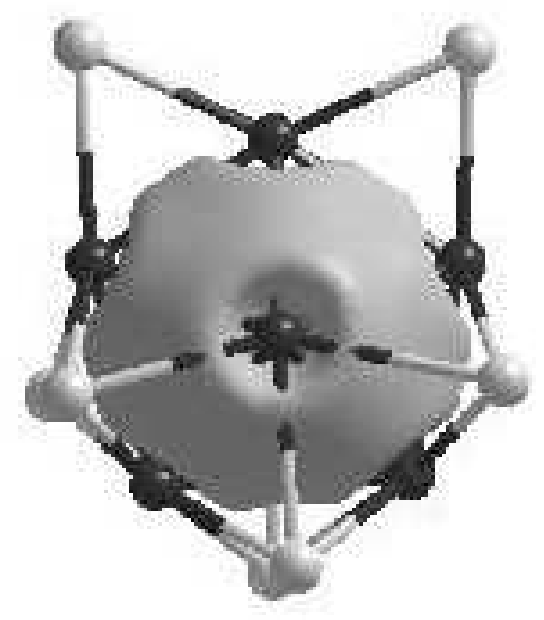

(a)

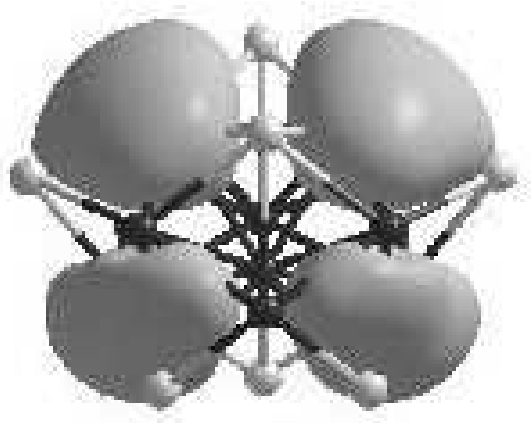

(c)

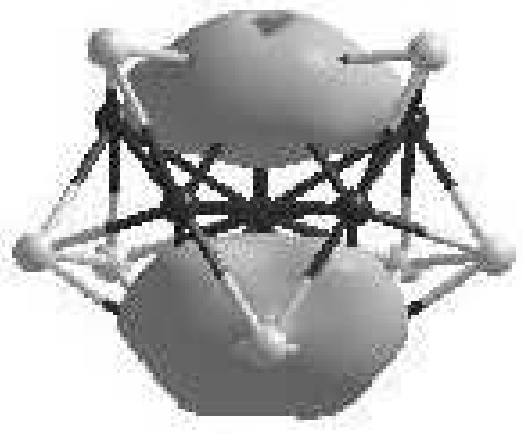

itsi

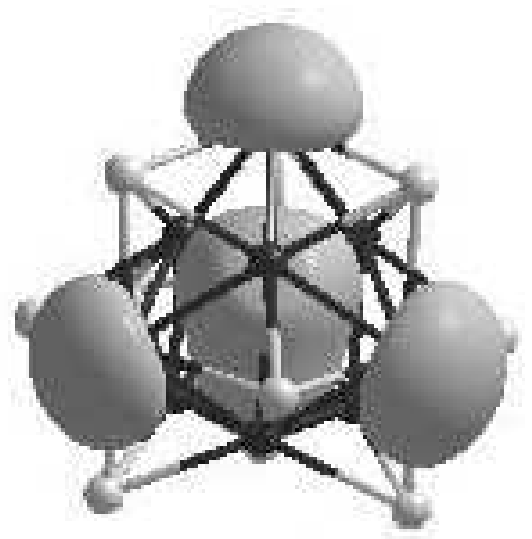

idi:

FIG. 8 .

FIG. 8 . 


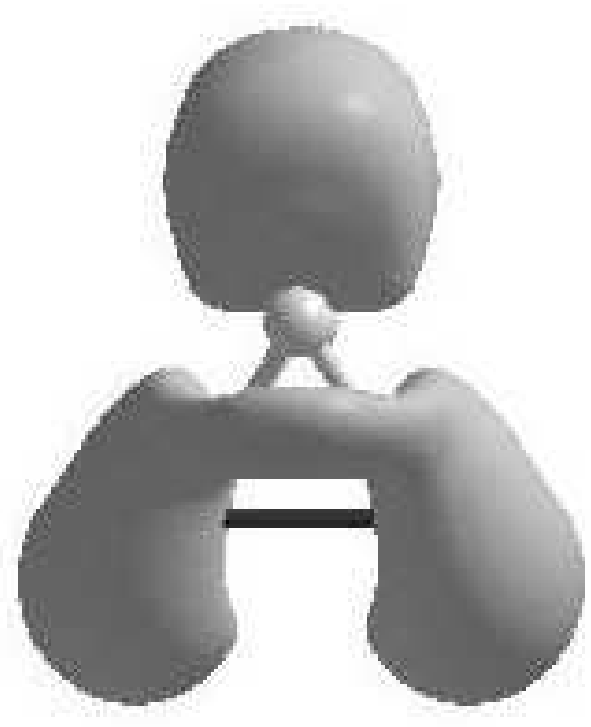

(a)

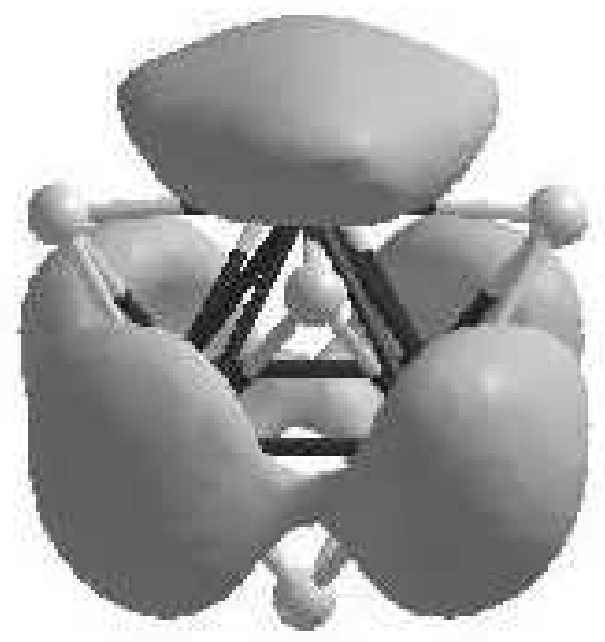

(i):

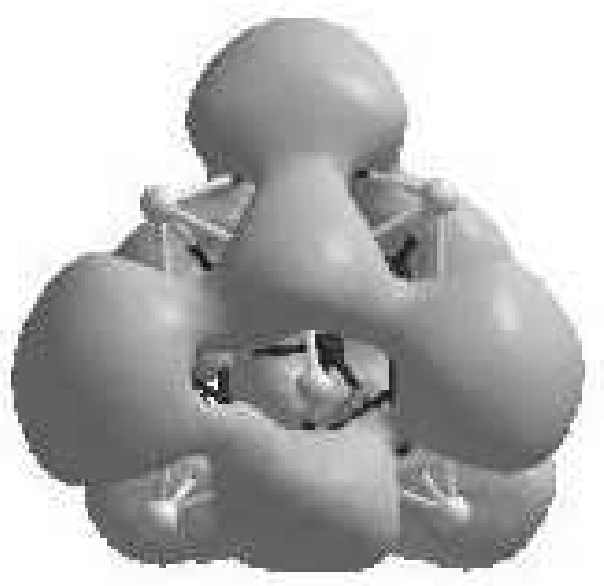

(i)

FIG. 9 .

FIG. 9. 